\title{
O material didático digital para o ensino de inglês e a promoção de multiletramentos
}

Raquel Rodrigues, mestranda,

Universidade Federal do Rio de Janeiro

Rogério Tílio

Universidade Federal do Rio de Janeiro

\begin{abstract}
Resumo
Este artigo tem como base um projeto de pesquisa de mestrado na linha de discurso como prática social. A proposta é analisar materiais didáticos digitais para o ensino de inglês para refletir, teorizar, além de apontar falhas e possíveis soluções para a elaboração de tais materiais de forma que promovam multiletramentos.
\end{abstract}

Palavras-chave: material didático digital, ensino de inglês, multiletramentos.

\begin{abstract}
This article is based on a Masters' research project, the line of work being discourse as social practice. The aim is to analyze digital materials for English Language Teaching in order to reflect, produce theories, and reveal flaws as well as possible solutions for the production of materials that actually promote multiliteracies.
\end{abstract}

Keywords: learning materials, ELT, multiliteracies.

\section{INTRODUÇÃO}

O material didático, como todo e qualquer texto, está imbuído de e em práticas discursivas desde o processo de produção, passando pela distribuição até seu consumo, e estas práticas discursivas, por sua vez, estão situadas historicamente em práticas sociais específicas, como o ensino de língua. A relevância do material didático vai muito além de seu conteúdo linguístico, ele pode exercer influência metodológica sobre práticas pedagógicas em sala de aula, assim como uma influência ideológica em seu discurso, isto é, sobre o social, sobre o mundo e sobre valores.

Este artigo apresenta uma análise de uma aula disponibilizada online para o ensino de inglês nos últimos anos do ensino fundamental na escola pública brasileira. O material analisado está disponível no Portal do Professor ${ }^{1}$, uma iniciativa do Ministério de

\footnotetext{
i. http://portaldoprofessor.mec.gov.br/fichaTecnicaAula.html?aula=49770.
} 
Educação (MEC) em parceria com o Ministério da Ciência e Tecnologia (MCTI) no site do MEC. O estudo é parte de uma dissertação em desenvolvimento no Programa Interdisciplinar de Linguística Aplicada da Universidade Federal do Rio de Janeiro.

A investigação teve início devido a uma inquietação da autora com relação à forma em que as novas tecnologias têm sido utilizadas para complementar o material didático impresso, e também com relação à elaboração de materiais didáticos, pela autora, para o ensino de inglês na escola pública do município do Rio de Janeiro nos anos finais do ensino fundamental, em um projeto como professora colaboradora em uma editora. Após alguma experiência em utilizar e criar materiais didáticos digitais, tornou-se importante entender os princípios teóricos e as práticas que deveriam ser adotadas. Tornou-se clara também a importância da função social que os materiais deveriam e poderiam exercer, em concordância com os documentos oficiais, como os Parâmetros Curriculares Nacionais (PCNs) e o Programa Nacional do Livro Didático (PNLD), que não aprovou nenhum material digital para o ensino de língua estrangeira até a presente data.

\section{ABORDAGEM TEÓRICA}

Considerando o momento sócio-histórico em que vivemos, os objetivos da Linguística Aplicada contemporânea (MOITA LOPES, 2006) e dos documentos oficiais (BRASIL 1997, 1998, 2013), adoto uma abordagem teórica sociointeracional (VYGOTSKY, 1978 [1998]) e a Análise Crítica do Discurso (FAIRCLOUGH, 1992 [2001]) para gerar e analisar os dados da pesquisa. Esta escolha apresenta-se como própria para avaliar materiais didáticos de uma perspectiva social e discursiva para além do aspecto meramente linguístico ou metodológico. Tal abordagem permite também teorizar sobre os caminhos que gostaríamos de trilhar para a elaboração de tais materiais na contemporaneidade. A opção por tais paradigmas é também uma decisão política e de princípios éticos.

A teoria de aprendizagem sociointeracional vê o ensino como uma prática sociocultural, que oportuniza situações de interação com o outro e com o meio devido ao "papel dominante da experiência social no desenvolvimento humano" (VYGOTSKY, 1978 [1998]: 26). De acordo com essa teoria, a aprendizagem efetiva e crítica é 
promovida através de oportunidades do aluno se engajar sociodiscursivamente no processo, co-construindo entendimentos e seu próprio discurso na interação social. Vygotsky afirma que "o momento de maior significado no curso do desenvolvimento intelectual (...) acontece quando a fala e a atividade prática (...) convergem" (VYGOTSKY, 1978 [1998]: 29).

Uma maneira que tanto os PCNs e o PNLD apontam como ponto de partida ideal para o ensino de inglês dentro dessa perspectiva é a abordagem de temas relevantes e includentes (TÍLIO, 2011). Dentre os temas que são relevantes trabalhar pode-se citar os Temas Transversais a todas as disciplinas, sugeridos para os últimos anos do ensino fundamental pelos PCNs: as questões da Ética, da Pluralidade Cultural, do Meio Ambiente, da Saúde, da Orientação Sexual e do Trabalho e Consumo. Conforme afirmado nos PCNs:

\begin{abstract}
Amplos o bastante para traduzir preocupações da sociedade brasileira de hoje, os Temas Transversais correspondem a questões importantes, urgentes e presentes sob várias formas na vida cotidiana. O desafio que se apresenta para as escolas é o de abrirem-se para o seu debate. (BRASIL, 1998:17)

Para o ensino de inglês é bastante simples trabalhar temas em aula e no material didático, afinal todo texto se refere a alguma coisa (BAKTHIN, 1929 [2006]). Devemos aproveitar então para usar textos diversos relacionados a temas relevantes e includentes, que possibilitem a participação ativa dos alunos nos debates pertinentes a suas vidas. No caso particular de inglês há uma disponibilidade enorme de textos autênticos dos mais diversos tipos na internet, basta selecioná-los criteriosamente e elaborar atividades para explorá-los ao máximo. A questão dos temas também se presta a honrar uma questão ética bem expressa nos documentos oficiais:
\end{abstract}

O compromisso com a construção da cidadania pede necessariamente uma prática educacional voltada para a compreensão da realidade social e dos direitos e responsabilidades em relação à vida pessoal e coletiva e a afirmação do princípio da participação política. (BRASIL, 1997:15)

Uma maneira de apresentar os temas através de textos (não se limitando à linguagem escrita na forma impressa ou digital, mas também oral, visual, em semioses multimodais, e de preferência refletindo diversidade cultural e linguística) em conformidade com as terias sociointeracionais seria abordá-los em seus gêneros. Afinal, como afirma Bakhtin, todo texto se organiza em gêneros do discurso, isto é, "tipos relativamente estáveis de enunciados" (BAKHTIN, 1979 [2003]: 262) Outra característica dos gêneros é a riqueza e a variedade destes. 
A riqueza e a variedade dos gêneros do discurso são infinitas, pois a variedade virtual da atividade humana é inesgotável, e cada esfera dessa atividade comporta um repertório de gêneros do discurso que vai diferenciando-se e ampliando-se à medida que a própria esfera se desenvolve e fica mais complexa. (BAKTHIN, 1979 [2003]: 279)

Essa característica faz com que possamos contemplar, na análise e na elaboração de materiais didáticos, novos gêneros que surgiram com o advento da internet, por exemplo. O meio digital oferece uma interface multimodal para o material didático através da hipermídia, que permite ir além do linguístico, acompanhando o hibridismo nas formas de linguagem e em termos midiáticos que vem sido contemplados pela Linguística Aplicada contemporânea (MOITA LOPES, 2006).

Da mesma forma, o letramento promovido pelo material didático também não deve ser meramente linguístico, devemos buscar promover multiletramentos, termo cunhado pelo New London Group, que tem por origem os múltiplos canais de comunicação, ou seja, diferentes mídias e semioses. Ainda dentro da ideia de multiplicidade, o conceito abraça também a diversidade cultural e linguística. A comunicação nos dias de hoje deixou de ser primariamente linguística para ser multimodal (COPE \& KALANTZIS, 2000).

Uma das características dos multiletramentos é a importância do letramento crítico, ou seja, a conscientização crítica do uso da linguagem, em especial quanto ao papel constitutivo do discurso. (FAIRCLOUGH, 1992 [2001]). Dentro do entendimento sociointeracional de que a linguagem não existe isolada, mas que está sempre situada em práticas discursivas e sociais, e que a aprendizagem e desenvolvimento se dão na interação, é importante que, no material didático, as atividades sejam verdadeiras tarefas de interação com o outro e com o meio através da linguagem, ou seja, que reflitam a visão do discurso como prática social. Sendo assim, as atividades devem ser tarefas que se assemelhem a práticas sociodiscursivas da vida real, que os alunos possam ser úteis a curto e médio prazo, não se restringindo apenas a conhecimentos que talvez possam ser aproveitados num futuro distante.

A Análise Crítica do Discurso (ACD), adotada como instrumental teóricometodológico, pode ser entendida como uma forma de análise que conecta a análise textual a contextos sociais e interacionais mais amplos, com o objetivo de mostrar "como a língua participa de processos sociais" (FAIRCLOUGH, 1992 [2001]: p. 229). Outra 
característica que a torna apropriada para o estudo repousa no fato de se constituir de um método para análise multidimensional, um método multifuncional, um método de análise histórica (FAIRCLOUGH, 1992 [2001]: 27).

Desta forma, o quadro teórico fornecido pela Teoria Social do Discurso de Fairclough (FAIRCLOUGH, 1992 [2001]) oferece o instrumental ideal para esta pesquisa, que busca investigar práticas discursivas e sociais desejáveis no ensino de inglês e que estas práticas seriam impulsionadas pelo material didático digital ideal, e as promovidas pelo material disponível através de seu discurso. A abordagem é também própria para teorizar sobre como superar a lacuna entre práticas sociodiscursivas desejáveis e as que o material possibilita.

\section{METODOLOGIA}

Como toda pesquisa qualitativa de base interpretativista, o estudo pretende construir entendimentos sobre uma situação específica (DORNYEI, 2006).

A geração de dados contou com a elaboração e aplicação de um checklist (Fig. 1) para avaliação de materiais disponíveis online e a seleção de uma aula que pudesse ser encontrada na internet e elaborada para os últimos anos do ensino fundamental. Os critérios do checklist foram embasados nos aportes teóricos, isto é, nas teorias sociointeracionais, nas de multiletramentos, de gêneros discursivos, da ACD e da Teoria Crítica do Discurso de Fairclough, buscando investigar se as práticas desejáveis são contempladas no material. 


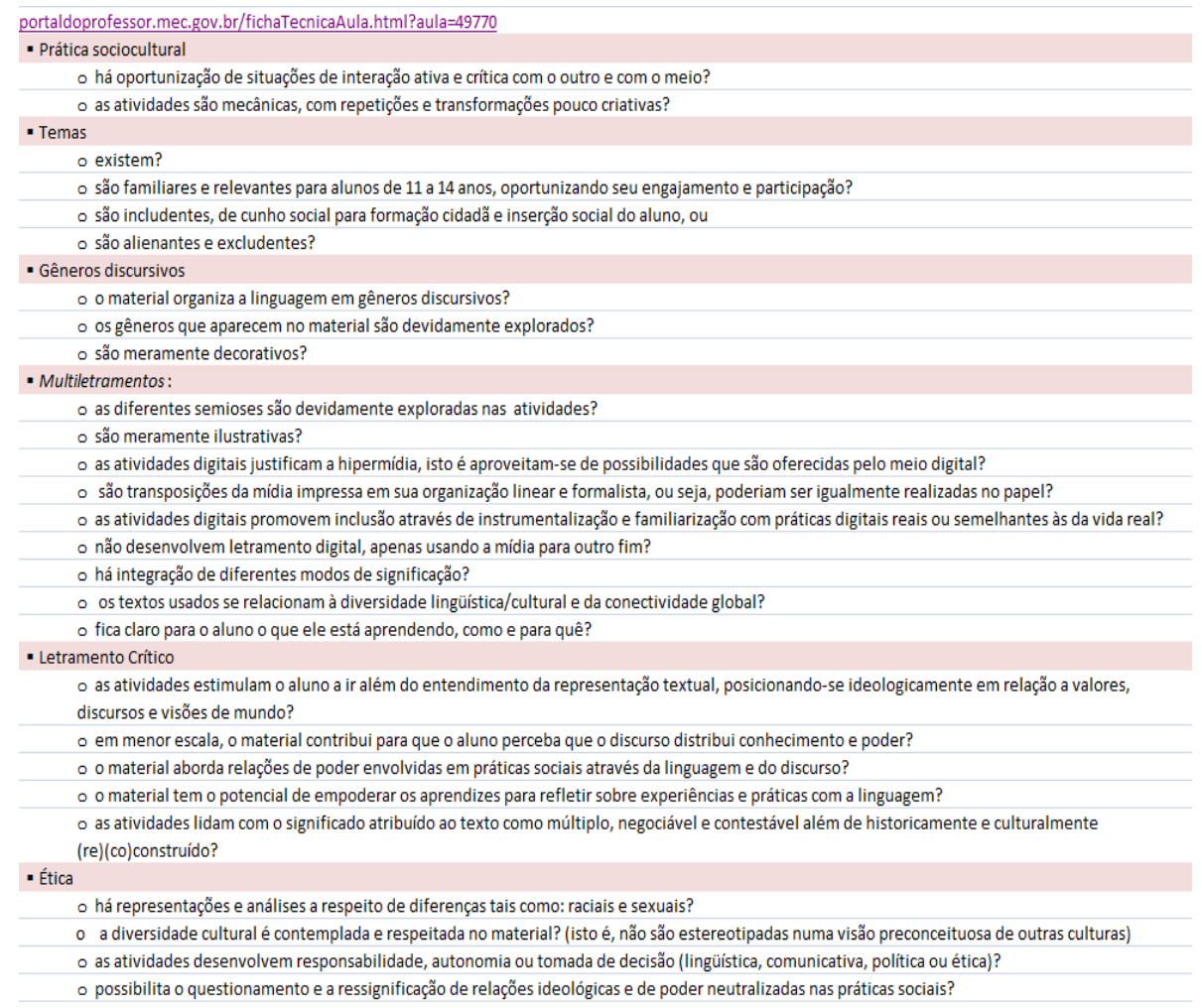

Fig. 1: Checklist elaborado pela autora para a geração de dados

O checklist foi, então, aplicado a uma aula disponível online no Portal do Professor. Previamente à seleção da aula a ser analisada foi feita a observação de diferentes aulas em dois sites. Uma limitação foi excluir o material disponível para o Ensino Fundamental 2 encomendado pela Secretaria Municipal de Educação do Rio de Janeiro (SME-RJ) na seleção por não considerar ético utilizar, uma vez que eu trabalhei na elaboração de grande parte deste material.

A escolha da aula analisada, entre oito observadas nos sites no período de geração de dados, se deu pelo fato de que essa aula aparenta, pela observação e experiência, ser bastante representativa de falhas que motivaram a pesquisa e, simultaneamente, passível de adaptação para atender aos critérios estipulados.

\section{ANÁLISE DE DADOS}

A análise a seguir segue a ordem das seções de perguntas do checklist elaborado.

\section{Prática sociocultural}


As atividades propostas na aula online são, na maioria, atividades mecânicas e pouco criativas, que poderiam conferir ao aluno um papel mais ativo, e às atividades um significado mais imediato e autêntico. Afinal, testam um entendimento único esperado do aluno em sua leitura do texto, porém há três instâncias de atividades mais livres, abertas e de interação. A primeira atividade, por exemplo, consiste em uma série de perguntas para gerar uma discussão em torno do conhecimento prévio do tema e opinião, valorizando a participação dos alunos e seu conhecimento de mundo. A maioria das perguntas se aproxima de uma tarefa reflexiva, porém relativamente superficial.

Uma sugestão de tarefa poderia ser pesquisar na internet alternativas sustentáveis para adotar no dia-a-dia, ao invés de utilizar um questionário com perguntas diretas, como é feito no material (Do you separate the litter at home? Do you try to walk, use public transport or ride a bicycle as much as possible?). A pesquisa poderia ser planejada com a turma toda contribuindo com sugestões de palavras-chave para a busca e de sites. O professor poderia fazer uma pesquisa prévia para mostrar aos alunos medidas tomadas em centros comunitários ao redor do mundo para poupar recursos naturais e até mesmo para economizar dinheiro.

Após uma pesquisa no laboratório de informática, os alunos poderiam se juntar em grupos para eleger as medidas mais eficientes que cabem ao cidadão, na opinião deles. Por fim, o professor poderia conduzir um debate sobre o alcance de medidas individuais e coletivas, se devem incluir órgãos governamentais, sobre qual o papel do governo e o que cabe ao cidadão para reverter os danos ambientais e provocar mudanças sociais. Poderia ser proposta a elaboração de um projeto sustentável para a escola, e se possível na comunidade em que ela se insere.

\section{Tema}

O tema da aula é relevante e inclusivo, pois além de ser um dos temas transversais sugeridos nos PCNs, as questões do meio-ambiente dizem respeito a todos. A atual crise ambiental e climática, um dos principais efeitos colaterais do desenvolvimento nãosustentável, é uma questão primordial de discussão nos mais diversos âmbitos da sociedade, porém o tema não é explorado e aprofundado tanto quanto seria possível e desejável, dado que o material trata do tema superficialmente, sem promover reflexão crítica. 
Os alunos devem ter acesso a diferentes discursos sobre o assunto e o material didático pode promover oportunidades para que eles possam desenvolver um instrumental para analisar esses discursos em sala de aula, co-construindo seus entendimentos em torno do debate, prestando atenção sempre em quem os diferentes discursos favorecem e quais ideologias podem estar sendo construídas neles.

\section{Gêneros discursivos}

O texto trabalhado na aula é apresentado de forma totalmente descontextualizada. Há um hiperlink para a fonte, porém o texto não é um artigo de revista online, não é uma postagem num blog ou em rede social, o link leva a um website de ensino de inglês administrado por uma pessoa que alega deter os direitos do conteúdo. Portanto, parece ser um texto feito para uso em sala de aula.

O gênero não é explorado. Apenas em uma das perguntas, na segunda parte da atividade 5, a serem respondidas com 'verdadeiro' ou 'falso', o texto é referido como “o artigo". Até então, os enunciados mencionam "o texto" sem sequer situá-lo em um gênero. Em nenhum momento o texto é contextualizado em uma prática sociocultural. Não é questionado o tipo de mídia onde poderia ser encontrado, a quem possa se dirigir e por quem teria sido escrito, muito menos com que propósito. $\mathrm{O}$ material não evidencia nem aborda as características do gênero.

Uma sugestão de texto multimodal para trabalhar o tema seria o vídeo Story of Stuff. Considero o texto multimodal, pois é composto de vários elementos linguísticos e não-linguísticos, elementos audiovisuais, gestuais e gráficos. O vídeo aborda economia e sustentabilidade de forma bastante didática e crítica. O filme está disponível no YouTube $^{2}$ e no site do projeto $^{3}$. Poderia ser trabalhado o interesse da autora e seu posicionamento ético e político, assim como trabalhar um texto que dê voz a outra perspectiva contrária, para que os alunos possam confrontá-los e posicionar-se.

\section{Multiletramentos}

A primeira atividade mostra uma imagem e uma lista de perguntas, as últimas das quais remetem à figura. Em outra atividade há uma imagem semelhante, porém servindo apenas para decorar o material para que fique mais atraente. Muitas vezes no livro

\footnotetext{
ii $h t$ ttp://www.youtube.com/watch?v=9GorqroigqM

iii. http://www.storyofstuff.org/movies-all/story-of-stuff/
} 
didático a imagem é utilizada dessa forma, meramente decorativa. O material analisado mostra vantagem ao dirigir, na primeira atividade, uma pergunta para os significados da semiose imagética tão presente na sociedade pós-moderna e tão importante como um dos aspectos dos multiletramentos.

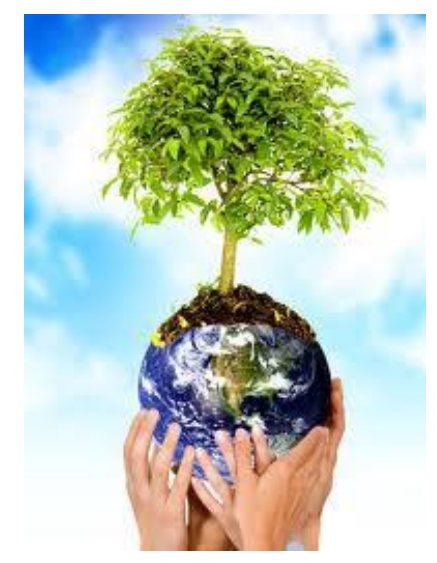

Fig. 2: Imagem utilizada no material

As perguntas para discussão relativas à imagem são: Como você descreveria $a$ imagem acima? O que ela sugere a você? A questão explora a imagem como texto, como fonte de significado múltiplo, negociável e contestável, oportunizando letramento visual, porém parcial, pois não vai além da significação pessoal para o significado social. Apesar da falta de reflexão crítica na atividade, a referência à imagem nas perguntas para discussão, promovendo interação com participação ativa dos alunos e aberta a significados múltiplos (sem uma resposta "correta"), aponta um progresso em relação a outros materiais observados. O letramento visual poderia ser propiciado ao incorporar perguntas como: Nas mãos de quem está a responsabilidade ambiental? Quem pode reverter os danos causados até agora e buscar novas formas da sociedade se relacionar com o meio-ambiente de forma sustentável? De que forma?

Enquanto o letramento visual está próximo do desejável, o letramento digital ainda está longe de tal mérito. Primeiro, a aula se assemelha a uma página de apostila escaneada, com pouca interatividade e apenas alguns hiperlinks remetendo às fontes dos textos (escritos e imagéticos), das atividades e de recursos complementares, além de três dicionários de inglês-português. Os links de recursos complementares levam a quatro sites sobre as mesmas estratégias de leitura (skimming and scanning) e um link para um vídeo disponível no 
YouTube também metateórico, sendo inadequado ao tipo de aprendiz em questão. Os quatro primeiros endereços eletrônicos exibem também transposições para a hipermídia que poderiam estar em mídia impressa em todos os seus aspectos. O vídeo do YouTube, por sua vez, se assemelha às lições dos telecursos oferecidos na década de 1980, com transmissão de conhecimento em forma oral e expositória.

A aula é um recorte e colagem semelhante a um handout digitalizado, de forma que não se justifica a mídia. O texto escrito e duas atividades são recortes de uma aula disponível em um site de ensino de inglês, e outra atividade (inclusive com erro ortográfico) foi transposta de um livro didático impresso. Apenas as imagens foram extraídas de um contexto autêntico: a ferramenta de busca de imagens do Google. De todos os hipertextos, os únicos a serem usados para navegação pelos alunos ao longo da aula são os dicionários online. A única atividade que apontaria para o letramento digital é a avaliação que seria feita através de cartazes virtuais, porém a autora da aula não disponibiliza uma ferramenta da internet através da qual se possa elaborá-los ou mesmo compartilhá-los. Para que houvesse de fato letramento digital, os alunos deveriam interagir entre eles e com outros através da mídia digital em práticas sóciodiscursivas autênticas, e o material poderia, e deveria, dar instrumentos para isso.

Existe uma ferramenta online chamada Glogster onde alunos podem fazer cartazes virtuais com texto, imagem e vídeo. Uma tarefa que poderia ser proposta seria ir ao site www.glogster.com ver alguns cartazes feitos mundo afora, e então, em grupos, elaborar os seus. A tarefa incluiria perguntas para guiar a pesquisa: Quais palavras-chave devemos usar na busca do site para encontrar cartazes relacionados ao nosso tema? $O$ que podemos esperar dos cartazes virtuais? Depois: Quais as características de um cartaz interessante, atraentemente eficiente em expressar a mensagem? Quais as características que talvez devêssemos evitar dentro do gênero?

\section{Letramento crítico}

Conforme apontado em comentários anteriores, as atividades não estimulam o aluno a ir muito além do entendimento da representação textual, posicionando-se ideologicamente em relação a valores, discursos e visões de mundo. Há perguntas de opinião para discussão em torno do tema, o que faz com que caminhe para isso, porém são questões superficiais. 
A primeira pergunta da primeira atividade da aula é Você acha que nosso planeta está em perigo? O material poderia, e deveria, ir além para abordar relações de poder envolvidas em práticas sociais através da linguagem e do discurso da seguinte maneira: Enquanto algumas pessoas, como a autora do vídeo Story of Stuff, se empenham em provar que há uma crise ambiental, outras se procuram provar que o aquecimento global é uma mentira. Você acha que há algum interesse de alguma das partes em ocultar a verdade da população? Para qual fim alguém mentiria a respeito de algo tão importante? O material poderia empoderar os aprendizes para refletir sobre experiências e práticas com a linguagem, porém não o faz.

\section{Ética}

Não há representações e análises a respeito de diferenças, tais como raciais e sexuais. A diversidade cultural não é contemplada no material e as atividades não desenvolvem responsabilidade, apenas questionam hábitos dos alunos em algumas perguntas. Autonomia e tomada de decisão linguística e comunicativa são estimuladas, em parte, quando os alunos devem elaborar suas perguntas sobre o texto e elaborar o pôster virtual, porém não há andaimamento para que eles possam desenvolvê-los. Não são estimuladas a tomada de decisão política ou ética.

A aula é sobre um tema inclusivo, porém com uma abordagem alienante com relação às questões ideológicas pertinentes ao tema, e, dessa forma, não possibilita o questionamento e a ressignificação de relações ideológicas e de poder neutralizadas nas práticas sociais.

\section{CONSIDERAÇÕES FINAIS}

A questão discutida busca entendimento sobre como o material didático pode contribuir para um ensino de inglês no Brasil que seja mais relevante e em compasso com o momento sócio-histórico em que vivemos. O material didático para o ensino de inglês é percebido como uma prática social que atualmente, apesar de esforços governamentais e não governamentais, reproduz práticas discursivas excludentes e alienantes.

As instituições de ensino, as aulas de inglês e a produção de materiais didáticos no país 
tradicionalmente promoveram e ainda promovem, em geral, um discurso que se exime de relacionar as práticas escolares e pedagógicas com a realidade do aluno e da sociedade em que estamos inseridos e de problematizar tais relações. Esse discurso não é neutro, ele é totalizante e hegemônico e, desta forma, só contribui para a manutenção do status quo político, econômico e social de desigualdade, passividade e exclusão.

Espero que este estudo possa contribuir para a futura elaboração de materiais digitais de ensino de inglês dentro de um novo paradigma político, ético e pedagógico emancipatório, inclusivo e transformador que, de fato, promova multiletramentos, fomentando o desenvolvimento de cidadãos críticos. Acredito que a pesquisa possa trazer tais contribuições na medida em que assinala a importância de estabelecer critérios éticos com fundamentação teórica para avaliação e elaboração de materiais didáticos digitais.

Pretendo, no curso de mestrado, acrescentar à análise de materiais a elaboração de trabalhos multimodais que atendam aos critérios do checklist, com o foco na promoção de multiletramento, e que justifique o uso da mídia digital. Espero, com esta discussão, acrescida de tais intervenções, co-construir entendimentos que possam ajudar a trilhar um caminho para que, em breve, vejamos materiais digitais consistentes com práticas relevantes para a formação de cidadãos críticos.

\section{REFERÊNCIAS}

BAKHTIN, M. M. [1952] Os gêneros do discurso. In: BAKHTIN, M. M. [1979] Estética da criação verbal. 4 ed. São Paulo: Martins Fontes, 2003

BAKHTIN/VOLOCHINOV [1929] Marxismo e filosofia da linguagem. 12 ed. São Paulo: Hucitec, 2006.

BRASIL. Ministério da Educação, Secretaria de Educação Básica. Guia de livros didáticos: PNLD 2014: língua estrangeira moderna: ensino fundamental: anos finais. Brasília: MEC/SEB, 2013. Disponível em http://www.fnde.gov.br/arquivos/category/125-guias?download=8322:livrolinguaestrangeira

BRASIL. Ministério da Educação, Secretaria de Educação Fundamental. Parâmetros curriculares nacionais: introdução aos parâmetros curriculares nacionais. Brasília: MEC/SEF, 1997. Disponível em http://portal.mec.gov.br/seb/arquivos/pdf/livro01.pdf

BRASIL. Ministério da Educação, Secretaria de Educação Fundamental. Parâmetros curriculares 
nacionais: terceiro e quarto ciclos do ensino fundamental: temas transversais. Brasília, 1998. Disponível em http://portal.mec.gov.br/seb/arquivos/pdf/ttransversais.pdf

BRASIL. Ministério da Educação, Secretaria de Educação Fundamental. Parâmetros curriculares nacionais: apresentação dos temas transversais, ética. Brasília, 1998. Disponível em http://portal.mec.gov.br/seb/arquivos/pdf/livro081.pdf

DORNYEI, Z. Research Methods in Applied Linguistics. Oxford, OUP: 2007.

FAIRCLOUGH, N. [1992] Discurso e mudança social. Brasília, UnB: 2001.

FRIDMAN, M. Vertigens pós-modernas: configurações institucionais contemporâneas. Rio de Janeiro: Relume Dumará, 2000.

MOITA LOPES, L. P. Linguística Aplicada e vida contemporânea: problematização dos construtos que têm orientado a pesquisa. In: MOITA LOPES, L. P. (Org.) Por uma Linguística Aplicada Indisciplinar. São Paulo: Parábola, 2006.

RAJAGOPALAN, K. Repensar o papel da Linguística Aplicada. In: MOITA LOPES, L. P. (Org.) Por uma Linguística Aplicada Indisciplinar. São Paulo: Parábola, 2006.

THE NEW LONDON GROUP. A pedagogy of multiliteracies: designing social futures. In: COPE, Bill; KALANTZIS, Mary (Eds.). Multiliteracies: literacy learning and the design of social futures. London \& New York: Routledge, 2000.

TÍLIO, Rogério. Linguística (Aplicada), contemporaneidade e materiais didáticos: diálogos. Caderno de Resumos II Colóquio Regional de Linguística Aplicada, 2011.

TÍLIO, Rogério. O livro didático de inglês em uma abordagem sócio-discursiva: culturas, identidades e pós-modernidade. Rio de Janeiro, 2006. 258p. Tese de Doutorado Departamento de Letras, Pontifícia Universidade Católica do Rio de Janeiro.

VYGOTSKY, L. S. [1978]. A formação social da mente. 7 ed. São Paulo: Martins Fontes, 2007.

\section{OS AUTORES}

Raquel Rodrigues, mestranda, UFRJ

E-mail: mzrodriguez@gmail.com

Rogério Tílio (orientador), doutor, UFRJ

E-mail: rogeriotilio@letras.ufrj.br 